
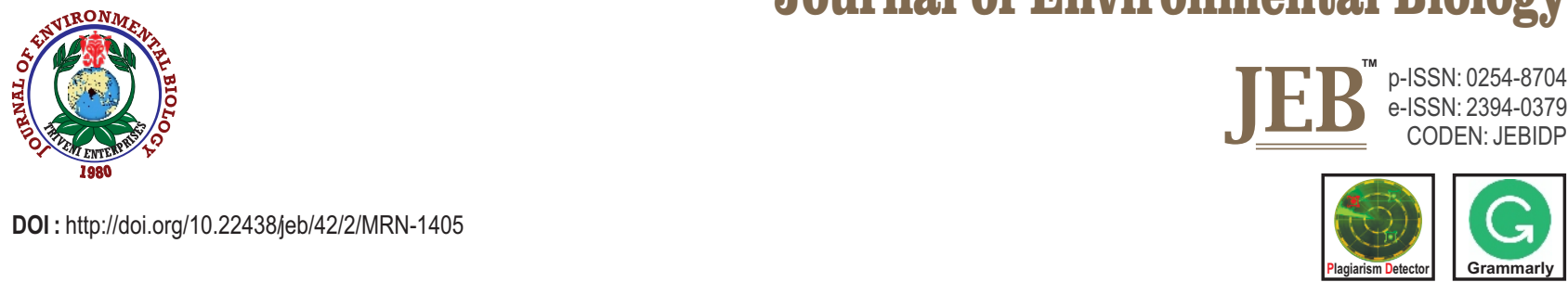

\title{
GGE biplot analysis of vegetable type soybean genotypes under multi-environmental conditions in India
}

\author{
V. Nataraj, N. Pandey, R. Ramteke, P. Verghese, R. Reddy, T. Onkarappa, S.P. Mehtre, S. Gupta*, G.K. Satpute, Y. Mohan, M. \\ Shivakumar, S. Chandra and V. Rajesh
}

ICAR-Indian Institute of Soybean Research, Indore-452 001, India

*Corresponding Author Email : sanitaishu@gmail.com

\section{Abstract}

Aim: To understand the magnitude and pattern of genotype-environment interaction in vegetable type soybeans and to identify mega environment(s) and best performing genotype(s) across environments.

Methodology: Five vegetable type soybean genotypes were evaluated across five geographical locations viz., Indore, Parbhani, Adilabad, Bengaluru and Pune, during rainy season of 2018. Genotypes were grown in a plot size of 1.35 $\times 3 \mathrm{~m}^{2}$ in three replications in randomized block design. Data on green pod yield, green seed test weight, days to $50 \%$ flowering, days to maturity and plant height were recorded using standard methods. GGE biplot analysis was performed using software "GGE Biplot version 7.0"

Results: In the present investigation, except in case of green seed test weight, in remaining four traits, major portion of variation was contributed by location $(52.95-79.4 \%)$ followed by genotype (17.7-42.7\%) and genotype x location interaction (2.21-4.29\%). Through GGE biplot analysis, Bengaluru was found to be near ideal environment and genotypes Karune and Harasoya were found to be the best performers across the locations with respect to green pod yield.

Interpretation: Bengaluru was found to be near ideal environment for vegetable type soybean evaluation. Selection for genotypes having wider adaptability can be conducted at this location. Genotypes Karune and

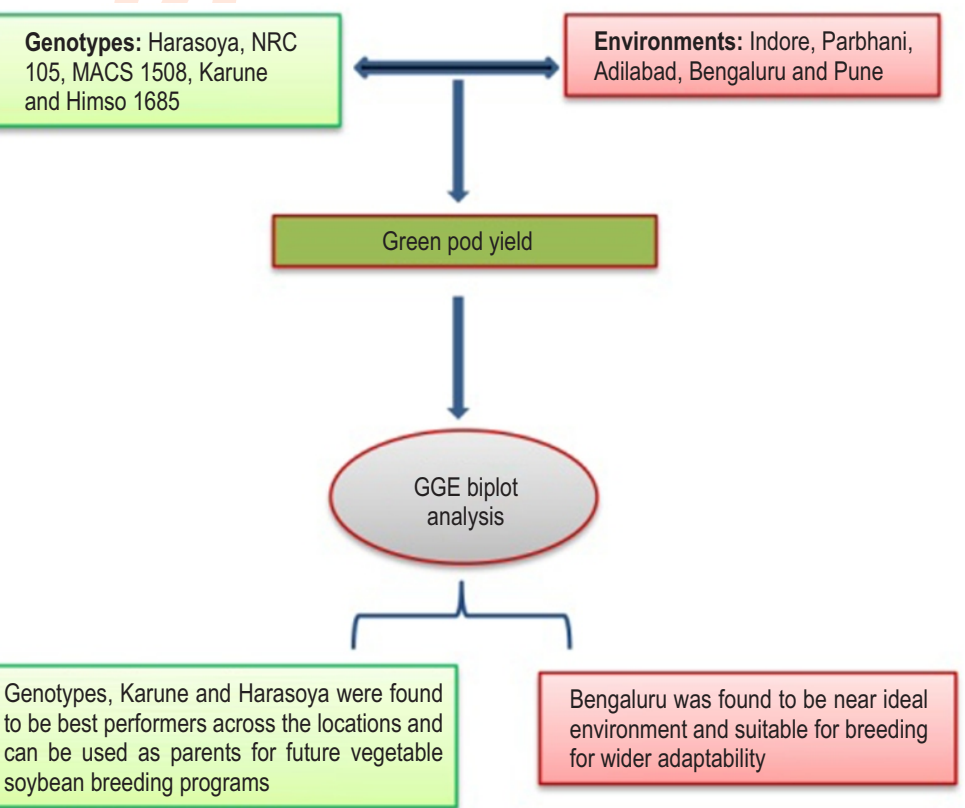
Harasoya were found to be the best performers with respect to green pod yield. These two genotypes can be included as parents for breeding as vegetable type soybean.

Key words: GEE biplot, Multienvironmental analyses, Soybean genotypes

How to cite : Nataraj, V., N. Pandey, R. Ramteke, P. Verghese, R. Reddy, T. Onkarappa, S.P. Mehtre, S. Gupta, G.K. Satpute, Y. Mohan, M. Shivakumar, S. Chandra and V. Rajesh: GGE biplot analysis of vegetable type soybean genotypes under multi-environmental conditions in India. J. Environ. Biol., 42, 247-253 (2021). 


\section{Introduction}

Soybean (Glycine max, L.) is the leading oil seed crop in the world. It is a short day crop grown under rainfed conditions in India. Vegetable soybean is a food grade soybean type with pleasant flavor and bold-seeded, harvested at R6-R7 growth stage when pods are green and seeds are immature (Zhang et al., 2010). It is a potential source of nutraceuticals, essential amino acids and isoflavones that promote human health. (Velasquez and Bhathena, 2007; Li et al., 2012; Lee et al., 2017). It is the only vegetable food source for all the essential amino acids and serves as a potential replacement for animal protein diet (Singh et al., 2019a). Net protein utilization value (NPU) is highest in cooked vegetable soybean as compared to soy-products and it contains $60 \%$ more calcium and twice the levels of phosphorus and potassium as compared to green peas Keatinge et al. (2011) reported that vegetable soybean produces highest crop protein yield per unit area and intake of $25 \mathrm{~g}$ of soy protein per day may minimise the risk of even heart disease (Fukushima, 2001). Reports say that $91 \%$ of vegetarians in India suffer from Proteinenergy Malnutrition (PEM) (Kulavoor et al., 2019). PEM has become one of the major health disorder in children, affecting their health, intellect, scholastic achievements, productivity and earning ability (Patidar and Jain, 2019). Therefore, large scale adoption and consumption of vegetable soybean can fight nutrient deficiency prevalent in Indian diet (Talukdar and Shivakumar, 2016).

Breeding for improved vegetable soybean and its sustainable production are the thrust areas in combating malnutrition and in achieving nutritional security. Hybridization and selection are the basic principles of plant breeding. Breeding for vegetable soybean was modest till recent past. At Indian Council of Agricultural Research- Indian Institute of Soybean Research (ICAR-IISR), Indore, we have initialized a separate vegetable soybean breeding program through All India Coordinated Research Project (AICRP) on Soybean. During 2018, five vegetable soybean genotypes were evaluated for different agronomic traits at five geographical locations. Multi environmental (years and locations) plant varietal trials are usually conducted to study differential performance of genotypes under different environmental conditions (Yan and Tinker, 2006). However, data generated from it has rarely been utilized to their fullest capacity. Furthermore, genotype evaluation is based on only genotype main effect $(G)$ treating genotype $x$ environment interaction (GE) as a noise or confounding factor (Yan and Tinker, 2006). It may be kept in mind that while evaluating genotypes both $G$ and GE must be taken into consideration (Yan and Tinker, 2006; Sabaghnia et al., 2008). Among different methods employed in understanding GE, GGE biplot analysis is most effective (Yan, 2002 Dias et al., 2003 and Ma et al., 2004).

GGE biplot analysis is being exploited in different crops such as soybean (Yan and Rajcan, 2002; Bhartiya et al., 2018), mungbean (Jeberson et al., 2019), rice (Samonte et al., 2005), wheat (Kaya et al., 2006; Singh et al., 2019b), barley (Dehgani et al., 2006), lentil (Sabaghnia et al., 2008), sorghum (Rakshit et al., 2012) in multi-environmental trials. Although, Chen et al. (2007) studied stability analysis in vegetable soybeans using AMMI model, to our knowledge, current study is the first attempt of study GE patterns in vegetable soybean using GGE biplot analysis. As a case study, current study utilized AICRPS data of five vegetable soybean genotypes at five test locations for genotypic and environmental evaluation through GGE biplot analysis. In view of the above, this study was carried out to investigate the genotype by environment interactions, to identify ideal and mega environments and ideal genotypes for their further utilization in vegetable soybean breeding programs.

\section{Materials and Methods}

A sub set of data from vegetable trial of AICRPS program was used for the current study. During rainy season 2018, five vegetable type soybean genotypes were evaluated in three replications across five locations viz., Indore (E1), Parbhani (E2), Adilabad (E3), Bengaluru (E4) and Pune (E5). Details of genotypes used in this study are presented in Table 1. At each location, trial was carried out in randomized block design in a plot of size $1.35 \times 3 \mathrm{~m}^{2}$. Standard crop management practices (ICAR, 2009) have been followed across all the locations. Data on days to $50 \%$ flowering, days to maturity and plant height were recorded using standard methods (IBPGR, 1984).

Green pod yield and green seed test weight were recorded at $R_{6}$ stage (Fehr et al., 1971). Green pods from each plot were harvested and weighed using electronic balance. A random sample of hundred green seeds from each plot was weighed using analytical digital lab balance. Green pod yield per plot $\left(\mathrm{kg} / 4.05 \mathrm{~m}^{2}\right)$ was converted to green pod yield per hectare $(\mathrm{kg}$ $\left.h a^{-1}\right)$. Analysis of variance was done using $\mathrm{R}$ package 'dplyr' (Wickham et al., 2019). Further analyses were done using software "GGE Biplot version 7.0" (Yan et al., 2000). Data interpretation was done by following Yan and Tinker (2006).

\section{Results and Discussion}

Analysis of variation (ANOVA) was carried out for five agronomic traits under consideration in five genotypes trialed at five test locations. It indicated that except for green seed weight, all other traits under study exhibited significant genotypic $(G)$, environment $(E)$ and genotype $x$ environment interaction (GE) effects (Table 2). For green seed weight only genotype $x$ environment interaction was significant. Relative contribution of each source of variation ( $G, E$ and $G E$ ) to total variation $(G+E+G E)$ is presented in Table 2 .

Usually in multi-environmental trials, major portion of variation is explained by environment (Gauch and Zobel, 1997; Kaya et al., 2006 and Dehghani et al., 2006). Likewise, in the present study, except for the trait green seed test weight, remaining four traits showed variation largely due to location effects $(E)$, followed by genotypic effects $(G)$ and genotype $x$ environment interaction effects (GE). For days to flowering, $E$ explained $52.95 \%$ of total variation followed by G $(42.76 \%$ ) and GE $(4.29 \%)$. In case of days to maturity, $79.48 \%$ of total 
Table 1: Pedigree details of genotypes

\begin{tabular}{lll}
\hline Genotype & Code & Pedigree \\
\hline Harasoya & G1 & Himso 1520 X Bragg \\
NRC 105 & G2 & GC99009-25-9-13GC95024-2-1x R75 \\
MACS 1508 & G3 & Himso 1563 x NRC 67 \\
Karune & G4 & Selection from GC00209-4-1-1 \\
Himso 1685 & G5 & Himso 330 x Hardee \\
\hline
\end{tabular}

variation was explained by $E$ followed by $G(17.70 \%)$ and $G E$ (2.81\%). Proportions of variation explained by $G, E$ and GE were $34.67 \%, 63.12 \%$ and $2.21 \%$, respectively, in case of plant height. For green pod yield, E attributed to $77.44 \%$ of variation, followed by $\mathrm{G}(19.49 \%)$ and $\mathrm{GE}(3.08 \%)$.

Similar trend was observed by Putto et al. (2008) while analyzing the yield in 17 peanut genotypes across 130 locations over 17 years. Rakshit et al. (2012) also reported major contribution of location followed by genotype and genotype $x$ interaction to the total variation in sorghum for the traits fodder yield, days to $50 \%$ flowering and harvest index. In case of soybean, Bhartiya et al. (2018) reported similar trend for grain yield, days to $50 \%$ flowering and days to maturity. In the present study, on contrary to the trend in other traits, in case of green seed test weight, variation was largely explained by $\mathrm{G}(90.38 \%)$, followed by E (8.10\%) and GE (3.08\%). Similar by, Bhartiya et al.
(2018) for 100 seed weight in soybean. This may be due to the effect of major QTLs governing seed weight confounded by maternal effects (Zhang et al., 2009 and Han et al., 2012). Genotype wise means for different traits under consideration are presented in the (Table 3). Since green pod yield is important trait for vegetable soybean, further analyses and interpretations were done only for this trait. Graphical visualization genotypic mean performance and stability of green pod yield was done through GGE biplots. First two principal components explained $95 \%$ of the total variation for green pod yield. Fig. 1a-e are the environmentvector view of environment centered (centering $=2$ ) and environment metric $(S V P=2)$ biplots. Fig. 1a explains the relationship among the test locations. Correlation between two environments is indicated by an acute angle between their environmental vectors. In current study, no obtuse or right angle between any of the two environment vectors has been observed and all the environments are correlated to each other.

However, the magnitude of correlations among the environments varied as represented through the cosine angle between them. E5 (Pune) is relatively less correlated with E3 (Adilabad) followed by E1 (Indore). Positive correlation among test locations indicated that same conclusions on genotype evaluation can be drawn from fewer locations resulting in reduction in cost and man power (Yan and Tinker, 2006). These results have to be validated across the years to reach out for a sub set of test locations for genotype evaluation without significant information loss. Discriminating ability of an

Table 2: ANOVA and percentage variation ( $G+E+G E)$ as explained by Genotype (G), Environment (E) and Genotype x Environment (GE) interaction for different agronomic traits

\begin{tabular}{lllll}
\hline Trait & & G & E & GE \\
\hline Days to Flowering & MS & $174.5^{* * *}$ & $216.067^{* * *}$ & $17.525^{* * *}$ \\
& Proportion of G+E+GE $(\%)$ & 42.76 & 52.95 & 4.29 \\
Days to Maturity & MS & $215.9^{* * *}$ & $969.43^{* * *}$ & $34.33^{* * *}$ \\
& Proportion of G+E+GE $(\%)$ & 17.70 & 79.48 & 2.81 \\
Plant Height (cm) & MS & $1043.44^{* * *}$ & $1899.71^{* * *}$ & $66.66^{* * *}$ \\
& Proportion of G+E+GE $(\%)$ & 34.67 & 63.12 & 2.21 \\
Green Seed Wight (g) & MS & 6769.2 & 607 & $113.2^{\text {*** }}$ \\
& Proportion of G+E+GE (\%) & 90.38 & 8.10 & 1.51 \\
Green Pod Yield (Kg ha $\left.{ }^{-1}\right)$ & MS & $42275954^{* * *}$ & $168001927^{* * *}$ & $6673582^{* * *}$ \\
& Proportion of G+E+GE(\%) & 19.49 & 77.44 & 3.08 \\
\hline
\end{tabular}

Table 3: Genotype wise means for different agronomic traits across locations.

\begin{tabular}{llllll}
\hline Genotype & Days to flowering & Days to maturity & Plant height $(\mathbf{c m})$ & $\begin{array}{l}\text { Green seed test } \\
\text { weight } \mathbf{( g )}\end{array}$ & $\begin{array}{l}\text { Green pod yield } \\
\left.\mathbf{( k g ~ h a}^{-1}\right)\end{array}$ \\
\hline Harasoya & $32.33(1.94)$ & $91.53(7.94)$ & $42.76(11.19)$ & $35.97(7.26)$ & $7950.93(3106.04)$ \\
NRC 105 & $30.46(2.94)$ & $86.13(6.43)$ & $28.8(9.31)$ & $73.54(9.80)$ & $4501.67(3550.35)$ \\
MACS 1508 & $36.73(5.10)$ & $92.8(8.45)$ & $45.94(10.50)$ & $27.22(5.38)$ & $7176.05(3981.55)$ \\
Karune & $30.93(3.78)$ & $87.93(10.90)$ & $43.41(11.65)$ & $72.37(6.92)$ & $9047.1(2764.20)$ \\
Himso 1685 & $37.86(7.20)$ & $95.6(8.61)$ & $51.32(17.17)$ & $43.93(11.28)$ & $7326.68(4376.30)$ \\
\hline
\end{tabular}

Figures in parentheses are standard deviations 

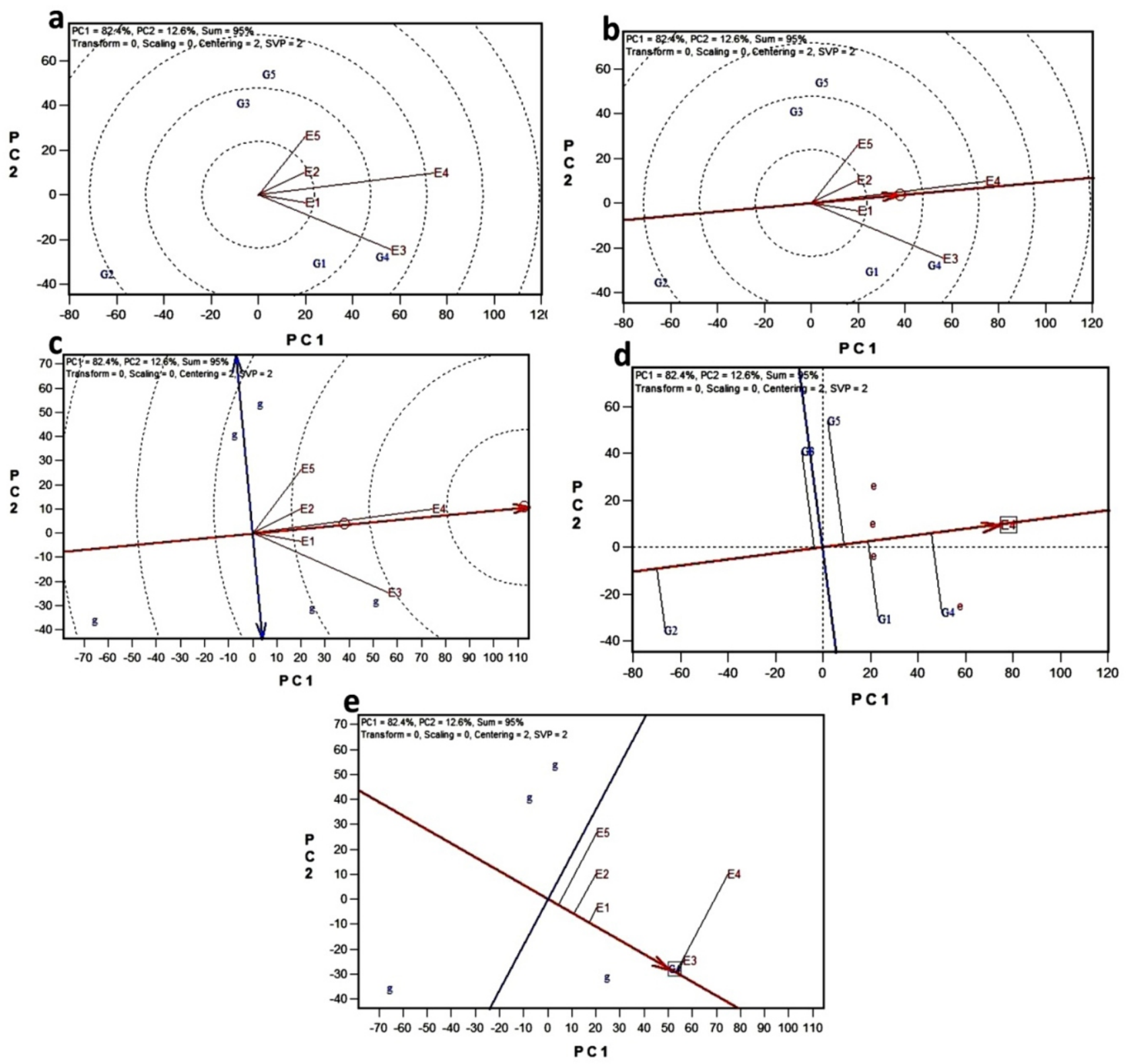

Fig. 1: Environment view of GGE biplot analysis: a: Relationship among the test locations; $b$ : Discriminativeness vs representativeness of test environments; c: Ranking of environments relative to an ideal test location (represented by the centre of the concentric circles); d: ranking of genotypes based on their performance in the near ideal environment E4 (Bengaluru); e: ranking of environments based on performance of best performing genotype, G4 (Karune).

environment is proportional to the length of respective environmental vector. In the present study, vector length of E4 (Bengaluru) was highest among the five. Therefore, E4 was the most discriminating environment followed by E3 (Adilabad), E5 (Pune), E2 (Parbhani) and E1 (Indore). Fig. 1b is the same biplot as of Fig. 1a except for the presence of AverageEnvironment Axis (AEA). A small circle at the end of the arrow of AEA represents the average environment. Environment vector with least deviation from AEA is considered to be most representative of other test locations. Therefore, E4
(Bengaluru) is the most representative whereas, E3 (Adilabad) and E5 (Pune) are the least representative. Locations E3 (Adilabad) and E5 (Pune) are discriminative but nonrepresentative. Such locations can be used for selecting genotypes having specific adaptability.

Breeding for wider adaptability requires selections sites, which are both discriminating and representative. In current study, E4 (Bengaluru) was found to be both discriminating and 

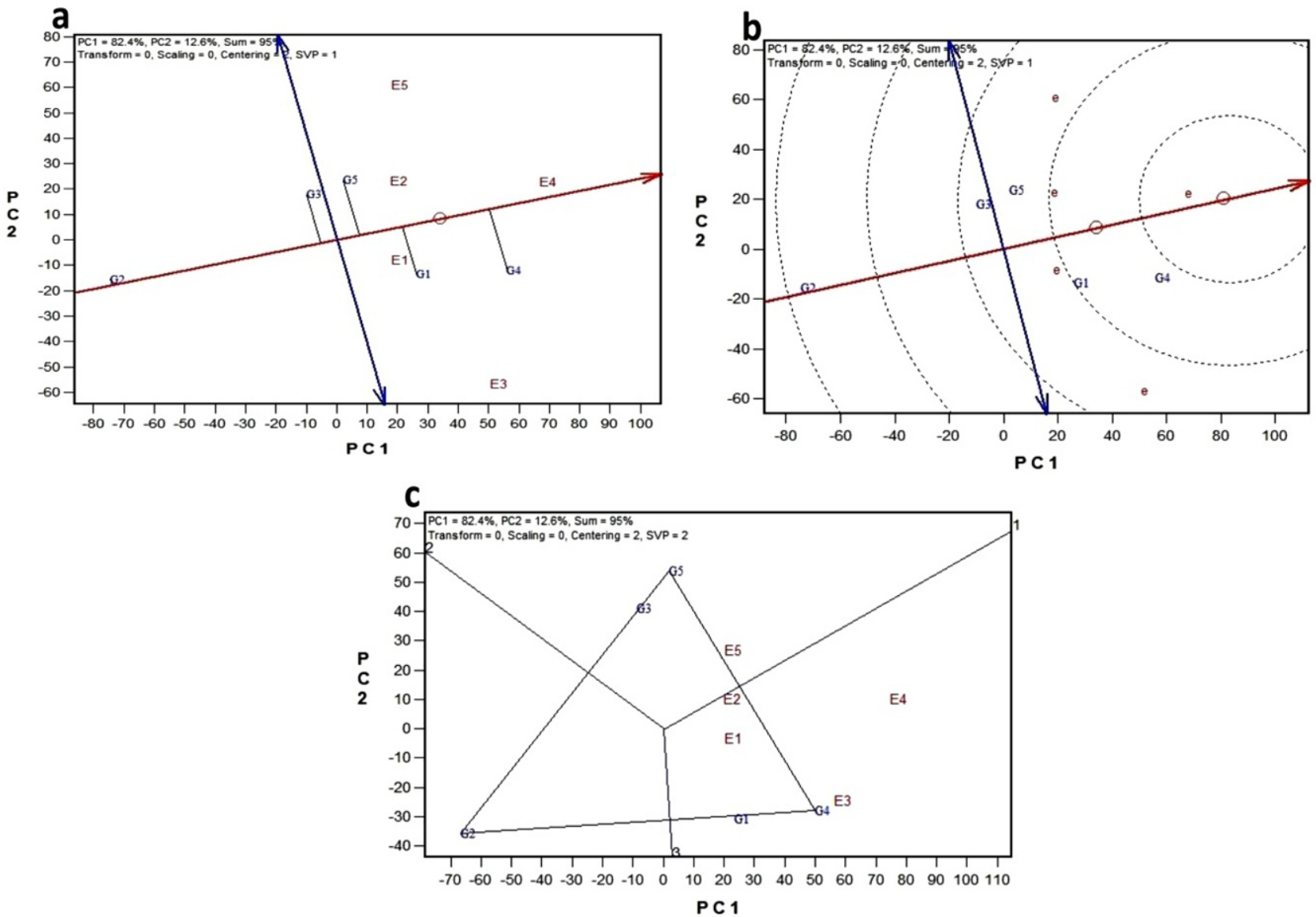

Fig. 2: Genotype view of GGE biplot analysis: (a) ranking of genotypes based on mean and stability; (b) ranking of genotypes relative to ideal genotype (centre of the concentric circles) and (c) Which-won-where analysis of genotypes.

representative and regarded best for selecting genotypes having wider adaptability. Centre of the concentric circles in Fig. 1c represents ideal environment for breeding wider adaptable genotypes. Environment vector closest to this point was assumed to be near ideal environment. In the present study, E4 (Bengaluru) was nearer to the ideal environment selecting for wider adaptable genotypes. Similarly, using GGE biplot analysis, ideal environments have been identified in wheat (Mohammadi et al., 2010), sorghum (Rakshit et al., 2012, Gasura et al., 2015) and rice (Donoso-Ñanculao et al., 2015). Fig. 1d depicts ranking of genotypes based on their performance in the near ideal environment E4 (Bengaluru). Genotypes G2 (NRC 105) and G3 (MACS 1508) had lower yield than the average whereas, genotypes G1 (Harasoya), G4 (Karune), and G5 (Himso 1685) had higher yield than the average. The highest yielder at E4 (Bengaluru) was G4 (Karune), while the lowest was G2. (NRC 105). To evaluate genotypes based on mean performance and stability across the test locations, average environment coordination (AEC) view of the environment-centered (centering=2) and genotype-metric (SVP=1) GGE biplot was employed (Fig. 2a). This biplot showed AEC abscissa, a single arrowed line pointing towards higher mean yield across test locations, AEC ordinate, a double arrowed line pointing towards poorer stability in either direction. Fig. 2a, revealed that G4 (Karune) and G1 (Harasoya) were the best performing genotypes in terms of green pod yield, followed by G5 (Himso 1685). Genotypes G2 (NRC 105) and G3 (MACS 1508) were found to be poor green pod yielders. On contrary to its poor yield potential, G2 was highly stable among the five genotypes. Though there was not much difference in stability among the remaining four genotypes, G1 (Harasoya) was relatively more stable among the four, followed by G5 (Himso 1685), G3 (MACS 1508) and G4 (Karune). Fig. 2b depicts ranking of genotypes relative to ideal genotypes.

A genotype with higher mean performance and stability across the test locations is said to be an ideal genotype. Centre of the concentric circles define ideal genotype; genotype more close to this point is regarded as near ideal genotype. In this study, genotype G4 (Karune) was more closer to the center, followed by G1 (Harasoya) and G5 (Himso 1685). Therefore, Karune may be regarded more close to ideal genotype. Similarly, using GGE biplot analysis, ideal genotypes have been identified in crops 
such as sorghum (Rakshit et al., 2012) and rice (DonosoÑanculao et al., 2015). Mean green pod yield of Karune across the locations was highest among the five genotypes, followed by Harasoya (Table 3). Fig. 1e represents ranking of environments based on performance of best performing genotype, G4 (Karune). It showed that G4 (Karune) had performed higher than average at all the locations. To identify which genotype performed best at which environment or set of environments and to differentiate test locations into mega environments, which-wonwhere feature of GGE biplot has been employed (Fig. 2c). Genotypes at each vertex of triangle are the best at corresponding environments. Perpendicular lines drawn from the biplot origin are the equality lines that differentiate test locations into different mega environments. Testing one or two representative locations within a mega environment can draw similar conclusions as that of testing at each location within a mega environment. This reduces the cost and resources for evaluation (Rakshit et al., 2012). In the current study, five locations were categorized into two mega environments.

One with location E5 (Pune) with G5 (Himso 1685) as best performing genotype and the other mega environment comprising of locations E1, E2, E3 and E4 with G4 as best performing genotype. However, consistency of this megaenvironment pattern has to be validated across years as done in case of wheat (Yan et al., 2000), groundnut (Putto et al., 2008) and pearl millet (Gupta et al., 2013). In the current study, an attempt was made to understand genotype by environment interaction pattern for green pod yield of vegetable soybean. Through GGE biplot analysis, it was found that Bengaluru can be regarded as near ideal environment for vegetable type soybean evaluation. Selection for genotypes having wider adaptability can be done at this location. Genotypes Karune and Harasoya were found to be the best performers with respect to green pod yield. These two genotypes can be included as parents for breeding for vegetable type soybean.

\section{Acknowledgment}

Authors are grateful to the Indian Council of Agricultural Research, New Delhi for financial assistance to conduct multi location trials through All India Coordinated Research Project on Soybean.

\section{Add-on Information}

Authors' contribution: V. Nataraj: Conceptualization, data analysis and manuscript preparation; N. Pandey, M. Shivakumar: Conceptualization, manuscript preparation; $\mathbf{R}$. Ramteke, Y. Mohan: Field trial at Indore; P. Verghese: Field trial at Pune; R. Reddy: Field trial at Adilabad; T. Onkarappa: Field trial at Bengaluru; S.P. Mehtre: Field trial at Parbhani; S. Gupta: Conceptualization, manuscript preparation; G.K. Satpute: Manuscript preparation; $\mathbf{S}$. Chandra: Manuscript preparation and technical inputs; V. Rajesh: Manuscript preparation.

Research content: The research content is original and has not been published elsewhere

Ethical approval: NotApplicable

Conflict of interest: The authors declare that there is no conflict of interest.

\section{Data from other sources: NotApplicable}

Consent to publish: All authors agree to publish the paper in Journal of Environmental Biology.

\section{References}

Bhartiya, A., J.P. Aditya, V. Kumari, N. Kishore, J.P. Purwar, A. Agrawal, L. Kant and A. Pattanayak: Stability analysis of soybean [Glycine $\max (\mathrm{L}$.) Merrill] genotypes under multi-environments rainfed condition of North-western Himalayan hills. Indian J. Genet., 78, 342-347 (2018).

Chen, Z., R. Hu and G. Lin: AMMI model analysis on regional test for new vegetable soybean varieties. Soybean Bull., 1, 32-33 (2007).

Dehghani, H., A. Ebadi and A. Yousefi: Biplot analysis of genotype by environment interaction for barley yield in Iran. Agron. J., 98, 388393 (2006).

Dias, C.T., S. Dos and W.J. Krzanowski: Model selection and cross validation in additive main effects and multiplicative interaction models. Crop Sci., 43, 865-873 (2003).

Donoso-Ñanculao, G., M. Paredes, V. Becerra, C. Arrepol and M. Balzarini: GGE biplot analysis of multi-environment yield trials of rice produced in a temperate climate. Chil. J.Agric. Res., 76, 152-157 (2015).

Fehr, W.R., C.E. Caviness, D.T. Burmood and J.S. Pennington: Stage of development descriptions for soybeans, Glycine max (L.) Merr. Crop Sci., 11, 929-931 (1971).

Fukushima, D.: Recent progress in research and technology on soybeans. Food Sci. Tech. Res., 7, 8-16 (2001).

Gasura, E., P.S. Setimela and C.M. Souta: Evaluation of the performance of sorghum genotypes using GGE biplot. Can. J. Plant Sci., 95, 1205-1214 (2015).

Gauch, H.G. and R.W. Zobel: Identifying mega-environment and targeting genotypes. Crop Sci., 37, 381-385 (1997).

Gupta, S.K., A. Rathore, O.P. Yadav, K.N. Rai, I.S. Khairwal, B.S. Rajpurohit and R.R. Das: Identifying mega-environments and essential test locations for pearl millet cultivar selection in India. Crop Sci., 53, 2444 (2013).

Han, Y., D. Li, D. Zhu, H. Li, W. Teng and W. Li: QTL analysis of soybean seed weight across multi-genetic backgrounds and environments. Theo. App. Genet., 125, 671-683 (2012).

ICAR: Handbook of Agriculture. Indian Council of Agricultural Research, New Delhi, pp. 1143-1150 (2009).

International Board for Plant Genetic Resources (IBPGR): Descriptors of soybean. IBPGR Secretariat, Rome, IBPGR 1984/84/183 (1984).

Jeberson, M.S., A.K. Parihar, K.S. Shashidhar, J. Dev, S.A. Dar and S. Gupta: Identification of suitable mungbean genotypes for hilly terrains of India using GGE and AMMI biplot approaches. J. Environ. Biol., 40, 1188-1195 (2019).

Kaya, Y.M., M. Akcurra and S. Taner: GGE-biplot analysis of multienvironment yield trials in bread wheat. Turk. J. Agr. Fors., 30, 325337 (2006).

Keatinge, J.D.H., W.J. Easdown, R.Y. Yang, M.L. Chadha and S. Shanmmugasundaram: Overcoming chronic malnutrition in a future warming world: The key importance of mungbean and vegetable soybean. Euphytica, 180, 129-141 (2011). 
Kulavoor, S., G. Ramugade and M. Subhashini: Development of protein rich product. Int. J. Adv. Res. Ideas Inn. Tech., 5, 274-277 (2019).

Lee, C.C., S. Dudonné, P. Dubé, Y. Desjardins, J.H. Kim, J.S. Kim, J.E. Kim, J.H. Park, K.W. Lee and C.Y. Lee: Comprehensive phenolic composition analysis and evaluation of Yak-Kong soybean (Glycine max) for the prevention of atherosclerosis. Food Chem., 234, 486-493 (2017).

Li, Y., M. Du, Q. Zhang, G. Wang, M. Hashemi and X. Liu: Greater differences exist in seed protein, oil, total soluble sugar and sucrose content of vegetable soybean genotypes [Glycine max (L.) Merrill] in North east China. Aus. J. Crop Sci., 6, 1681-1686 (2012).

Ma, B.L., W. Yan, L.M. Dwyer, J. Fregeau-Reid, H.D. Voldeng, Y. Dion and $H$. Nass: Graphic analysis of genotype, environment, nitrogen fertilizer, and their interactions on spring wheat yield. Agron. J., 96, 389-416 (2004).

Mohammadi, R., R. Haghparast, A. Amri and S. Ceccarelli: Yield stability of rainfed durum wheat and GGE biplot analysis of multienvironment trials. Crop Past. Sci., 61, 92-101 (2010).

Patidar, P.K. and N. Jain: Protein energy malnutrition. Int. J. Sci. Res., 8, 55-57 (2019).

Putto, W., A. Patanothai, S. Jogloy and G. Hoogenboom: Determination of mega environments for peanut breeding using the CSMCROPGRO-Peanut model. Crop Sci., 48, 973-982 (2008).

Rakshit, S., K.N. Ganapathy, S.S. Gomashe, A. Rathore, R.B. Ghorade, M.V.N. Kumar, K. Ganesmurthy, S.K. Jain, M.Y. Kamtar, J.S. Sachan, S.S. Ambekar, B.R. Ranwa, D.G. Kanawade, M. Balusamy, D. Kadam, A. Sarkar, V.A. Tonapi and J.V. Patil: GGE biplot analysis to evaluate genotype, environment and their interactions in sorghum multi-location data. Euphytica, 185, 465479 (2012).

Sabaghnia, N., H. Dehghani and S.H. Sabaghpour: Graphic analysis of genotype by environment interaction for lentil yield in Iran. Agron J., 100, 760-764 (2008).

Samonte, S.O.P.B., L.T. Wilson, A.M. Mc Clung and J.C. Medley: Targeting Cultivars onto rice growing environments using AMMI and SREG GGE biplot analysis. Crop Sci., 45, 2414-2424 (2005).

Singh, B.P., D. Yadav and S. Vij: Soybean bioactive molecules: Current Trend and Future Prospective. In: Bioactive Molecules in Food (Eds.: J.M. Mérillon and K. G. Ramawat), Reference Series in Phytochemistry, Springer Nature Switzerland AG, pp. 267-294 (2019a).

Singh, C., A. Gupta, V. Gupta, P. Kumar, S. Ramadas, B.S. Tyagi, G. Singh, R. Chatrath and G.P. Singh: Genotype x environment interaction analysis of multi-environment wheat trials in India using AMMI and GGE biplot models. Crop Bree. App. Bio., 19, 309-318 (2019b).

Talukdar, A. and M. Shivakumar: Genetic improvement of food-grade soybean in India: Current status and future prospects. Indian $\mathrm{J}$. Genet., 76, 626-630 (2016).

Velasquez, M.T. and S.J. Bhathena: Role of dietary soy protein in obesity. Int. J. Medi. Sci., 4, 72-82 (2007).

Wickham, H., R. François, L. Henry and K. Müller: dplyr: A Grammar of Data Manipulation. R package version 0.8.0.1. https://CRAN.Rproject.org/package=dplyr. (2019).

Yan, W.: Singular value partitioning for biplot analysis of multienvironment trial data. Agron. J., 4, 990-996 (2002).

Yan, W. and I. Rajcan: Biplot analysis of test sites and trait relations of soybean in Ontario. Crop Sci., 42,11-20 (2002).

Yan, W. and N.A. Tinker: Biplot analysis of multi-environment trial data: Principles and applications. Can. J. PI. Sci., 86, 623-645 (2006).

Yan, W., L.A. Hunt, W.Q. Sheng and Z. Szlavnics: Cultivar evaluation and mega-environment investigation based on the GGE biplot. Crop Sci., 40, 597-605 (2000).

Zhang, W., H. Xu and J. Zhu: Index selection on seed traits under direct, cytoplasmic and maternal effects in multiple environments. $J$. Genet. Geno., 36, 41-49 (2009).

Zhang, Q.Y., Q.L. Gao, S.J. Herbert, Y.S. Li and M. Hashemi: Influence of sowing date on phonological stages, seed growth and marketable yield of four vegetable soybean cultivars in Northeastern USA. Afr. J.Agric. Res., 5, 2556-2562 (2010). 